\title{
A educação sexual necessária
}

Nelson Vitiello ${ }^{1}$

Não se pode negar que a civilização está vivenciando, neste final de século, uma situação de crise que se manifesta em várias frentes; vivemos uma época de crise dos valores morais e éticos, uma crise econômica e política, e várias outras. Essa situação é resultante de um sem número de fatos ocorridos em nossa história longínqua ou recente, que condicionaram o surgir da atual fase.

Assim, numa simplificação extrema e só para citarmos alguns dos mais importantes, lembremos que a segunda metade do nosso século vem assistindo um acelerado processo de urbanização, como nunca se viu antes na história da humanidade. A América Latina, por exemplo, há curtos 20 anos, tinha apenas três de cada 10 de seus habitantes residindo em cidades. Por um processo social complexo ocorreu uma rápida mudança e hoje tem ela 7 de cada 10 de seus habitantes morando em áreas urbanas. Grandes cidades, com mais de um milhão de habitantes, são cada vez

1. Ginecologista. Título de Especialista em Educação Sexual concedido pela FLASSES (Federação Latinoamérica das Sociedades de Sexologia e Educação Sexual). 
mais comuns, chegando alguns centros, como São Paulo, à incrível concentração de quase seis rmilhões de habitantes por quilômetro quadrado. É claro que esse intenso processo de urbanização não se fez exclusivamente a custa do crescimento reprodutivo, mas também (e principalmente) pela migração de contingentes populacionais de áres rurais para as cidades.

Essa urbanização assim acentuada trouxe conseqüências para o estilo de vida das pessoas. Os grandes problemas urbanos - moradia, segurança, transporte, etc. - se agudizaram, fazendo que com eles se dispenda (no trânsito, por exemplo) uma considerável parcela de tempo, que de outro modo poderia ser dedicada à família ou ao lazer. As pessoas tendem progressivamente a se ensimesmar, cultivando um menor círculo de amizades; na realidade, temos cada vez mais conhecidos a cada vez menos amigos.

A própria constituição das famílias mudou. Daquela família estendida, em que conviviam num mesmo espaço três ou mais gerações, com grande número de indivíduos $e$ vários colaterais e agregados, passou-se à família nuclear, na qual convivem somente os pais (quando ainda não se separaram) e um ou dois filhos, que freqüentemente apenas se vêem rapidamente, na maioria dos dias. Essa mudança da estrutura familiar afroxou os laços de união entre seus membros e trouxe, como conseqüência, a quase total abolição da transmissão de conhecimentos, tradições e costumes entre as gerações. A cultura, em seu conceito antropológico, deixou de ser transmitida de geração à geração, pela crescente perda de prestígio das gerações mais idosas, que vêem seu papel de transmissor cultural cada vez mais ocupado pelos meios de comunicação de massa.

Esses meios - em especial a televisão - também se constituem em importante fator modificador da sociedade. Nunca antes em sua história a humanidade havia se defrontado com tão poderosos veículos de comunicação, que atingem sua máxima eficácia com a vulgarização a nível planetário da televisão, com a tecnologia dos satélites geo-estacionários. Pode-se hoje, em qualquer local do mundo, receber em casa (ou até mesmo na cama) imagens de fatos que estão ocorrendo ou que ocorreram a poucos minutos, no outro lado do mundo.

Os fatores aqui tão superficialmente citados contribuem, todos eles, para uma nova maneira de viver; não nos cabe (nem teria qualquer sentido) um julgamento de valores, no sentido saudosista de louvar os velhos tempos, ou de entoar loas às conquistas tecnológicas de nossa época. O que desejamos é, tão somente, assinalar que a sociedade mudou, e com ela mudamos todos nós adultos, crianças e adolescentes.

Dentre essas mudanças, sem dúvida assumem grande importância aquelas ocorridas no padrão de exercício da sexualidade, em especial entre os jovens, É muito difícil, senão impossível, estabelecer o número de adolescentes de ambos os sexos que vem se iniciando sexualmente nessa fase 
da vida. Os métodos de pesquisa empregados, principalmente quando se baseiam em informações fornecidas pelos próprios adolescentes, tendem a não refletir os números reais, pelo temor que os jovens tem sobre como serão usados os dados levantados por entrevistadores. Numa estimativa bastante modesta, a julgar pelas conseqüências possíveis do exercício da sexualidade (número de gestações, doenças sexualmente transmissíveis, etc.), podemos afirmar que ao menos a metade das moças e a quase totalidade dos rapazes, em nosso meio, iniciam-se sexualmente durante a adolescência. E, na imensa maioria das vezes, essa iniciação sexual é feita sem qualquer preparo, formal ou informal, que possa diminuir as probabilidades do advento de traumas, experiências frustrantes ou mesmo consequiências meramente orgânicas, como as doenças sexualmente transmissíveis ou a gestação inesperada.

No que toca a educação é importante que nos detenhamos, ainda que ligeiramente, sobre as origens de nossos sistema educacional.

Até o século XVII a infância não era sequer reconhecida como um período bem individualizado da vida humana. Nesse enfoque, a criança era vista apenas como um pequeno adulto, não recebendo uma educação específica $e$ tendo que, muito precocemente, conviver com o trabalho $e$ com as preocupações próprias dos adultos. Esses eventos, ligados à sociogênese da infância, aparecem com muita clareza quando estudamos o vestuário típico dessas épocas, bem como na análise do treinamento que as crianças - de qualquer classe social - recebiam.

Por volta do citado século, com o empobrecimento da nobreza e com a ascensão da burguesia, ocorreram movimentos de valorização da inocência, passando a ser exaltada a pureza infantil, dentro de todo um contexto social de revalorização de alguns movimentos religiosos. Compreendia-se então a prática do sexo como uma atividade pecaminosa e não merecedora de aceitação divina e social. As crianças, por não terem os genitais externos ainda desenvolvidos e por não praticarem atividades sexuais, estavam em estado de pureza, isentas assim de qualquer "culpa". Ainda dentro desse enfoque, acreditava-se ser essa "inocência" proveniente da ignorância sobre o sexo, sendo então defendida a postura da conservação dessa inocência pela manutenção da ignorância. A partir desses conceitos, foi valorizado um tipo de "educação" que ao mesmo tempo mantinha as crianças (e os adolescentes) desinformados e impunha-lhes um padrão repressor de comportamento, visando-se mantê-los afastadas da curiosidade e dos conhecimentos sobre a sexualidade. Os resquícios sociais de tais padrões educacionais podem ficar bem evidenciados na angústia que a maioria dos adultos atuais sofre frente às manifestações da sexualidade infantil, como a masturbação, por exemplo. E é esse ainda o padrão de educação vigente, que reprime ao mesmo tempo em que nega a sexualidade do ser humano durante a infância.

Uma conseqüência curiosa que esse enfoque ainda conserva é o freqüente uso de crianças em peças publicitárias as mais diversas, mesmo 
aquelas não dirigidas a um público infantil. Parte-se do principio que, como é inocente, a criança não pode mentir; assim, se recomenda um determinado produto é por que ele é realmente bom.

Nosso século tem assistido a importantes mudanças no que se refere aos padrões de enfoque da sexualidade e dos comportamentos sexuais. Embora exista ainda muita repressão, de maneira geral a sexualidade vem gradativamente passando a ser melhor compreendida, deixando de ser exercida quase sempre sem permissão social e usualmente condenada à clandestinidade.

$\mathrm{Na}$ atualidade admitimos que a sexualidade se manifesta desde o início da vida e que com ela se desenvolve, acompanhando o desenvolvimento geral do indivíduo.

\section{ALGUNS IMPORTANTES CONCEITOS}

Antes de podermos falar em "educação sexual", é importante que se deixe bem claros os conceitos de "informação", "orientação", "aconselhamento" e "educação", pois parece-nos haver multa confusão entre eles. Evidentemente a nomenclatura que propomos não é a única existente, e talvez nem mesmo a mais comum. No entanto, é a que nos parece mais funcional; por isso a adotamos.

A simples passagem de informações, embora muito relevante e de fundamental importância para o processo educativo não se constitui, em si mesma, nesse processo. Em outras palavras, fornecer a alguém informações sobre detemrinados fatos não é, isoladamente, um processo educativo, embora possa fazer parte desse processo. Informar é uma atividade de ensino, de instrução, e não de educação, ao menos enquanto a informação for passada isoladamente.

Já a orientação implica num mecanismo mais elaborado, segundo o qual, baseando-se em sua experiência e em seus conhecimentos, o orientador ajuda o orientado a analisar as diferentes opções disponíveis, tornando-o assim apto a descobrir novos caminhos.

Aconselhar, por outro lado, consiste em auxiliar o aconselhando a decidir-se por um ou por vários dos possíveis caminhos que ele próprio já conhece; em outras palavras, aconselhar significa "ajudar a decidir".

Educar, finalmente, embora possa passar por informar, por orientar e por aconselhar, é mais do que a soma dessas partes isoladas. Educar, no sentido mais amplo, significa "formar", não na acepção de que o educando seja uma cópia do educador, mas sim na de que o educador dá ao educando condições e meios para que cresça interiormente. A influência do educador, por isso mesmo, além de intensa precisa ser contínua e duradoura, 
pois caso contrário não conseguirá seu intento, embora todo e qualquer contato humano possa ter uma conotação educadora.

Exemplificando, todos nós tivemos, em nossa formação escolar, dezenas de professores; no entanto, em sua maioria, foram eles quase sempre meros repetidores de informações. Apenas um, ou no máximo alguns poucos, deixaram em nossa lembrança marcas perenes, cuja influência nos acompanha no decorrer de toda a vida. Esse, ou esses poucos, foram para nós verdadeiros educadores.

Nesse sentido, a educação sexual sistemática só pode ser feita por familiares ou por professores, pois apenas a família e a escola, como instituições sociais, conseguem preencher os pressupostos que explicitamos antes, isto é, só elas conseguem atuar de maneira contínua e duradoura. Se essa educação é de boa ou má qualidade, se é ou não satisfatória, é outro problema; o que é indiscutível é ser ela a única a se dar de forma sistemática. Já a educação sexual assistemática, ocasional, pode ocorrer de forma espontânea, no seio da própria sociedade (em grupos de parceria, por exemplo) ou mesmo de forma proposital, quando o educando procura por iniciativa própria freqüentar cursos, ler matérias ou assistir conferências sobre o tema.

Num parêntese, parece-nos conveniente deixar claros os conceitos de "autonomia" e de "liberdade", que são freqüentemente confundidos. Denomina-se de autonomia à aptidão para analisar as diversas opções de escolha disponíveis. Desde que desenvolva seu tirocínio e sua capacidade de pensar logicamente, está o jovem apto a fazer suas próprias escolhas. Isto não significa, no entanto, que possa ele exercer essa escolha, pois para isso lhe faltam condições materiais, financeiras, sociais, etc. Apenas quando adquirir essas condições poderá o jovem exercer livremente qualquer opção que tenha eleito; a isso se denomina habitualmente de "liberdade". Assim, pode-se dizer, a grosso modo, que os adolescentes tem autonomia, mas ainda não tem liberdade, que só será conquistada com sua completa emancipação, inclusive econômica.

Voltando à discussão do tema do papel do profissional na educação sexual, queremos deixar bem clara nossa opinião de que o médico, a enfermeira, o psicólogo ou o assistente social, quando fazem palestras em escolas, não estão exercendo verdadeiramente a educação sexual, mas sim funcionando como meros informadores. Claro que essas bem intencionadas tentativas são meritórias e funcionam no sentido de desmistificar o tema; são entretanto absolutamente contraproducentes enquanto medidas educadoras. Esses profissionais podem e devem fazer informação, orientação, aconselhamento ou até mesmo (no caso de médicos e psicólogos) terapia sexual. Continuamos a insistir, no entanto, que o caminho real para a educação sexual não é levar profissionais de várias áreas às escolas, mas sim preparar professores interessados para a tarefa de fazê-la. 


\section{EDUCAÇÃO SEXUAL}

Podemos agora, com esses conceitos firmados, passar a atratar especificamente da educação sexual.

É importante, inicialmente, que firmemos conceitos básicos, para bem situar o tema. Assim, tentaremos analisar o que se entende por educação sexual, pois se não tivermos claras idéias a respeito sem dúvida surgirão dificuldades no manejo do tema.

Como vimos, o processo de educação é bastante amplo, abrangente e complexo, compreendendo uma série de fases. Dentro dessa amplitude, que obrigatoriamente envolve o assumir uma série de atitudes, faz-se necessário que o educando também assuma comportamentos ligados à esfera da sexualidade, desempenhando um papel sexual. Educação Sexual seria, dentro desse amplo conceito, a parte do processo educativo especificamente voltada para a formação de atitudes referentes à maneira de viver a sexualidade.

Muitas vezes nos perguntamos, por exemplo, qual seria a causa de ainda existirem tantas gestações indesejadas e tantas doenças sexualmente transmissíveis, se o uso de métodos anticoncepcionais são na atualidade tão seguros, e o condom é tão simples, barato e de todos conhecidos. É-nos freqüientemente difícil explicar esses paradoxos.

Evidentemente não se trata apenas de falta de informação nem exclusivamente se falta de acesso ao uso esses métodos. O que falta é uma atitude, é um comportamento coerente de utilizá-los.

A atitude pode ser definida como sendo a disposição que uma pessoa tem para agir de forma favorável em relação a uma particular situação e depende não só de conhecimento mas também da forma como sentimos os fatos expressos per esse conhecimento. É dessa interação que se origina a maneira de agir, o comportamento de cada pessoa, pois a maneira de pensar de cada um depende muito de suas vivências e da maneira como decorreu seu aprendizado social.

Assim, se por exemplo alguém teve uma experiência negativa com o uso de um método anticoncepcional, ou se recebeu referências sobre efeitos desagradáveis de pessoas que estima e admira, este conhecimento e esta vivência terão um sentido particular para ela. Com base nessa particular maneira de sentir é que essa pessoa vai estruturar seu pensamento acerca desse método em particular, e até mesmo da anticoncepção em geral.

Não devemos nos esquecer que além do conhecimento, um processo que ocorre a nível consciente e racional, entram em jogo as crenças, que muitas vezes atuam no campo do irracional e até mesmo no do inconsciente. Enquanto o conhecimento apela para a lógica, a crença é baseada na aceitação acrítica de algo como sendo verdadeiro, independentemente de comprovações racionais. 
Nossos valores pessoais, que se constituem numa espécie de traçador de nossas linhas de conduta, dependem muito de conhecimentos a crenças. por isso, quando se valoriza alguma coisa -como a virgindade, per exemplo - tende-se a modelar a vida de acordo com este padrão de conduta, exigindo que as outras pessoas valorizem as mesmas coisas.

Além do conhecimento, entra também na formulação de nossas atitudes um forte componente afetivo, isto é, o sentimento ou reação emocional que um indivíduo apresenta com relação a um objeto ou situação. $\mathrm{O}$ que um adolescente pensa no tocante a anticoncepção em relação a estes temas. E o que o indivíduo pensa e sente é o motor de sua forma de agir.

Firmamos assim, mais uma vez, que a educação não pode se constituir só em informação, que é apenas um dos seus componentes. A educação, que compreende a modificação de atitudes, é algo bem mais amplo. Não é apenas fornecendo informações sobre a sexualidade que conseguiremos alterar os comportamentos das pessoas, pois conhecendo muitos fatos sobre sexualidade, contraceptivos ou métodos de prevenção de doenças sexualmente transmissíveis, as pessoas podem continuar a não usá-los. Aliás, para demomstrar que a mera informação não tem o poder de mudar comportamentos, basta lembrarmos que, apesar de saber dos malefícios do tabagismo - exaustivamente divulgados - muitas pessoas (até médicos a educadores) continuam fumando.

Evidentemente a informação é importante no processo educativo, que por ela obrigatoriamente passa, mas a ela não se limitando. O processo educativo deve, como já dissemos propiciar um crescimento de dentro para fora, num processo reflexivo, enquanto que a instrução é processo de aposição, em que o informando tem aumentados seus conhecimentos, sem que apenas com isso assuma novas atitudes e comportamentos. Ao informarmos estamos apenas transmitindo conhecimentos, que não serão necessariamente utilizados; ao educarmos, entretanto, estamos preparando o educando para a vida e despertando o potencial de humanização. Aliás, Santo Tomas de Aquino já dizia que educação não é algo que se transmita ao aluno, mas sim algo que nele se desperta.

Nesse ponto talvez caiba uma digressão, para deixar claro que EDUCAÇÃO SEXUAL, vista como algo autônomo, seguramente não existe, pois o conceito que estamos explicitando de EDUCAÇÃO é amplo demais para ser assim setorizado. Parece-nos importante dizer, embora pareça óbvio, que evidentemente existe um componente sexual na educação, embora a setorização que o termo "educação sexual" possa trazer deva ser compreendido como uma figura de retórica.

Ficando dito que a educação sexual é a preparação do indivíduo para a vida sexual, importa agora refletirmos sobre os seus objetivos, pois afinal quem educa o faz com uma determinada finalidade. Inegavelmente, 
per trás de todo processo educativo existe uma ideologia dominante, isto é, existem objetivos que se quer alcançar.

A educação, secularmente, tem sido utilizada pelos detentores do poder com a finalidade de nele se pertuarem, bem como de conseguir melhor exercê-lo. Regimes políticos mais democratizados, por outro lado, esforçam-se (ou ao menos deveriam se esforçar) para, através da educação, perpetuar o sentimento e a vivência das liberdades democráticas. De qualquer maneira, a educação pode ser usada para fins políticos, o que, na história da humanidade, é muito conhecido.

Outras vezes, a educação tem sido usada com finalidades religiosas ou sociais, ainda que com o risco de ser utilizada apenas para moldar as pessoas dentro de rígidos padrões culturais, aceitos pelo grupo dominante nessa sociedade em particular. Essa educação é extremamente sufocante e habitualmente infelicitante, não permitindo a contestação de valores e robotizando as pessoas.

No entanto, idealmente, devia a educação visar um processo de socialização e, ao mesmo tempo, preparar os indivíduos para assumirem o ônus dos processos de mudança, quando esses se fizerem necessários, o que seria uma posição equilibrada.

Evidentemente, a verdadeira educação deve ter um aspecto socializador, na medida em que prepara o indivíduo para viver em uma determinada sociedade. Ao mesmo tempo, entretanto, deve dotar a pessoa de instrumentos que permitam as mudanças culturais que se tornarem necessárias, aumentando sua capacidade crítica, para que ele seja capaz de, quando preciso, abandoar padrões e recriar a sociedade em moldes mais adequados.

\section{GRANDES MODELOS DE EDUCAÇÃO SEXUAL}

Em linhas gerais, podemos identificar 4 grandes modelos de enfoque para a educação sexual, que já foram e ainda são utilizados.

Modelo Demográfico: baseado nas doutrinas maltusianas e neomaltusianas, prioriza os aspectos referentes ao ensino dos métodos de controle da natalidade. Embora idealmente não seja meramente repressor, este modelo é freqüentemente utilizado como meio de exercer repressão sexual. Note-se, aliás, que o ônus e os riscos inerentes às práticas anticoncepcionais recaem habitualmente sobre as mulheres, sendo exercido até mesmo como uma forma de controlar a sexualidade feminina.

Modelo Médico: enfatiza a necessidade de que se ensine aos jovens a importância dos procedimentos ligados à preservação da saúde. Inserem-se nessa linha os projetos educativos que visam fundamental- 
mente a prevenção da AIDS. Freqüentemente este modelo de Educação Sexual também é utilizado como forma de repressão sexual, tendo-se em vista que torna o exercício da sexualidade como algo de arriscado e ameaçador. Se no antigo modelo religioso repressor da sexualidade, sexo era associado ao pecado, nesse modelo sexo é associado à morte.

Modelo Feminista: prioriza a busca da eqüidade de gênero, buscando dar a mulher maior liberdade no uso de sua sexualidade a lutando contra os preconceitos que pesam sobre elas. Em seus arquétipos mais radicais transforma a luta pela igualdade numa luta pela supremacia feminina. Suas vertentes socialistas equiparam a luta pelos direitos da mulher com a luta de classes, identificando no capitalismo um inimigo tão virulento quanto o machismo.

Modelo Humanista: coloca o processo educativo como meio de atingir a felicidade, priorizando o sexo prazeroso e sem vítimas, isto é, sem que se provoque danos aos outros nem a si mesmo. É o enfoque que nos parece mais correto.

Em nossa opinião, a educação sexual deve ter o objetivo de promover a felicidade, preparando as pessoas para usarem de maneira responsável sua liberdade, sendo assim um agente de promoção da felicidade individual e coletiva. Deve, em outras palavras, estar a serviço não só do indivíduo mas também no da sociedade.

A educação sexual, por isso, não deve manter-se dentro dos estreitos - embora importantes - objetivos de evitar gestações indesejadas ou doenças sexualmente transmissíveis, mas sim promover a felicidade sexual das pessoas. Deve-se educar para uma liberdade responsável, que faça com que o indivíduo não apenas busque seu prazer pessoal, mas respeite a liberdade sexual, os limites e a integridade do outro. Dentro desse objetivo, promover a luta contra preconceitos, evitar a AIDS e gestações indesejadas serão consequiências naturais.

Podemos dizer que idealmente a educação sexual deveria estar voltada para o amor, aqui não entendido simplesmente como mera atração física pelo outro, e nem mesmo como um amor româtico, que se conforma apenas em dar. Compreendemos o amor como um sentimento maduro, como um dar e receber, amar e se amado, enfim, como uma forma de comunicação e troca bilateral. Esse tipo de amor, que dignifica e torna muito mais prazeroso o exercício da sexualidade deve ser o alvo e a verdadeira finalidade de todo o preparo que envolve a educação sexual.

Considerando esses conceitos, analisemos qual seria a estrutura social que deveria assumir a responsabilidade da educação sexual.

Uma educação sexual feita de maneira informal e espontânea, sem planos rigidamente estabelecidos, é aquela propiciada pela família e por 
outras estruturas sociais, como as religiões, por exemplo. Nesse tipo de educação busca-se que as pessoas passem a ter um comportamento assumido por imitação. Sem entrar na discussão mérito desse tipo de educação, se é boa ou se é má, certa ou errada, e nem mesmo em seu valor intríseco, o fato é que, queiramos ou não, todos somos a ela submetidos. A família, principalmente, por ação ou por omissão sempre educa sexualmente suas crianças.

$\mathrm{Na}$ atualidade, os meios de comunidações de massa - notadamente a televisão - tem tido um importante papel como formadores de comportamentos os mais diversos, inclusive sexuais, tendo por isso mesmo um lugar de relevo nesse tipo de educação asistemática.

Por outro lado, a educação sexual formal, intencional, é aquela que é fornecida pelo sistema institucionalizado de educação, seja pela pré-escola, pela escola, pela Universidade, enfim, por qualquer das instituições de ensino formalizado. Nesse modelo se observam características de intencional idade, além de estratégia de ordenação gradativa de conhecimentos e toda uma tecnologia educacional.

Um meio termo entre esses dois tipos é aquela educação que, embora intencional, é promovida por estruturas que não fazem parte do sistema institucionalizado de educação, sendo oferecida através de conferências, cursos ou palestras para grupos interesados.

Todas estas modalidades educativas podem ser compatíveis.

Parece-nos claro que a melhor educação seria a que fosse propiciada pelos próprios pais, pois nenhuma estrutura social consegue atuar tão precocemente, com adultos tão significativos, por tanto tempo a de forma tão importante sobre o ser humano em sua fase de formação de personalidade, como a família.

No entanto, como regra geral, os pais tem notória dificuldade em falar de sexo com os seus filhos, embora possam ter facilidade para dar esclarecimentos a orientações, em geral liberais e liberalizantes, para os filhos dos outros; quando chega o momento de ensinar os próprios filhos, entretanto, surge importante inibição. São dificuldades de cunho cultural, que somente serão superadas com muito esforço pessoal e grandes lutas internas pois nós, adultos, somos inegavelmente filhos de nosso meio e de nossa época, sendo ao mesmo tempo agentes e vítimas dos preconceitos vigentes.

Assim sendo, pelas dificuldades enfrentadas pelos pais, somos obrigados a nos valer do ensino formal, que nos parece ser, a médio a longo prazo, a solução mais viável no momento histórico que nossa sociedade está vivendo. E mais, como as pessoas estão tendo sua iniciação sexual cada vez mais cedo, se quisermos que a educação idealmente atue de forma preventiva, devemos pensar em institui-Ia precocemente, motivo pelo qual deve ser priorizada já no ensino de primeiro grau. 
A metodologia a ser uiilizada em educação sexual, como em outras áreas, é preferivelmente a do ensino participativo, através de dinâmicas de grupos e discussões cujos temas devem ser escolhidos pelos próprios educandos, que muitas vezes tem necessidades de conhecimentos diferentes daquelas que nós, adultos, jugamos prioritárias.

No entanto, quem pode preparar adequadamente os educadores? Em outras palavras, QUEM EDUCA O EDUCADOR? Este parece-nos ser o ponto mais importante para a entrada em cena dos estudiosos da Sexualidade Humana sob seus vários aspectos, pois como todos sabemos, os cursos profissionalizantes, de maneira geral, muito pouco (ou talvez nada) ensinam sobre sexualidade, sequer sobre os preceitos mais básicos da anatomia e da fisiologia, quanto mais quanto ao comportamento. Nesse sentido, nossa participação na formação desses educadores é de enorme relevo.

A educação sexual nas escolas não deve, ou ao menos idealmente não deveria, se constituir em uma disciplina com provas, mas sim ser propiciada por um professor especialmente treinado, como educador que é, para a discussão participativa dos problemas ligados à sexualidade humana, sem a assumir postura de julgador do que é "certo" ou "errado" em matéria de sexo. Em nossa maneira de entender, a metodologia a ser utilizada para a educação sexual deve ter as seguintes características:

Participativa: deve haver comunicação horizontal entre todos os participantes, tendo todos iguais direitos de serem ouvidos e terem suas dúvidas discutidas. $\mathrm{O}$ ensino tradicional, baseado em doutas exposições teóricas e onde um (professor) ensina a os outros (alunos) aprendem, é reconhecidamente incapaz de promover mudanças de comportamento. Por isso, tanto os cursos de formação de educadores quanto os de educação sexual propriamente dita devem se lastrear principalmente em técnicas de dinâmicas de grupo.

Dialógica: o núcleo de atenção dessa metodologia deve ser livre diálogo, sendo todos os aspectos dos temas discutidos com ampla participação. Deve-se partir do princípio que todos, inclusive o "educador", tem algo a ganhar com o diálogo.

Baseada na realidade sócio-cultural: as situações devem ser apresentadas e analisadas dentro de um contexto sócio-cultura em que se valorize o quotidiano dos participantes. Assim, cada projeto de programa para educação sexual deve ser formulado após o conhecimento da realidade em que a comunidade alvo está inserida. Em outras palavras, de nada adiantam as fórmulas "prontas", importadas de outros meios.

Desenvolvida com criatividade: não devem existir fórmulas prontas, mas sim um roteiro genérico onde irão se inserindo, com criatividade, soluções para situações emergentes das discussões. 
Infimista: todos os participantes devem ter suas vivências pessoais compartilhadas, sem censura e sem julgamentos. Evidentemente, como em qualquer processo educacional, devem ser colocados limites. Estes, no entanto, devem ser sempre explicitados quando se formulam as bases do que será o "contrato didático" entre as partes.

Lúdica: finalmente, é importante que se acentue o lado lúdico da educação. É importante que fique claro para todos que o ganho de conhecimentos e o desenvolvimento de atitudes não precisa ser um processo aborrecido e desagradável. Devemos sempre lembrar que pode-se dizer sisudamente grandes asneiras e que, sorrindo, também se pode expressar grandes verdades.

Importa ainda realçar que a educação sexual somente alcançará o máximo de seus objetivos se a Escola, como uma instituição, a ela se dedicar. Devem idealmente receber treinamento todos os participantes do grupo social, do porteiro ao Diretor. Além disso, para maior alcance desses objetivos, são recomendáveis as reuniões prévias com os grupos de pais, que quando devidamente esclarecidos, na imensa maioria das vezes vêem com entusiasmo (e até mesmo com certo alívio) a iniciativa.

Dentre os atributos desejáveis para um educador sexual, podemos destacar:

\section{Adequadação sexual própria}

O tipo de preferência ou o modelo de exercício da sexualidade do professor não são de importância, desde que o mesmo esteja a ele adequado, sentindo-se feliz, e não tente apresentar esse modelo particular como o único correto aos seus educandos. Essa adequação pode ser encontrada até mesmo em pessoas com os denominados desvios sexuais, como os homossexuais, por exemplo, ou entre indivíduos que, por convicções religiosas se abstenham de relações sexuais, como os Padres da Igreja Católica. Desde que o educador esteja satisfeito com sua própria sexualidade e não tente impô-lo aos outros, está ele qualificado, a nosso ver, para exercer uma educação sexual adequada. Deve ainda ele ter a coragem de desafiar seus próprios tabus e preconceitos, reconhecendo suas próprias falhas.

\section{Facilidade de contato com jovens}

Em nossa opinião, o professor deve ser treinado para fazer o curso de educação sexual, é aquele que normalmente é o mais procurado pelos 
alunos para um conselho ou um esclarecimento, qualquer que seja a disciplina que ele habitualmente ministre, pois o simples fato de ser alvo de confiança dos jovens já demonstra possuir ele credenciais que o capacitam para exercer a atividade de educador sexual, devendo apenas ser adequadamente treinado.

\section{Abertura intelectual, moral e afétiva}

É fundamental que o profissional que se disponha a praticar educação sexual tenha abertura suficiente para não se arrogar o direito de julgar o que é certo ou errado no comportamento alheio, reconhecendo que ninguém é dono de verdades absolutas e eternas. A capacidade para amar o trabalho e os jovens sob sua orientação é uma valiosa qualidade, que deve ser prezada, preservada e até estimulada. Assim, é fundamental que o educador tenha sua adolescência perto de si - qualquer que seja sua idade cronológica - e que conserve sua capacidade de amar.

\section{Tolerância}

Conseguir conviver com modelos de comportamento diferentes do seu, conseguindo compreendê-los e aceitá-los é fundamental para que não se julguem, a priori, erradas outras formas de exercício da sexualidade. Deve o educador por isso cultivar em alto grau a tolerância, furtando-se dojulgamento fácil.

\section{Conhecimentos adequados}

Propositalmente deixamos este item para o final, não por julgá-lo menos importante mas sim por sabermos ser ele o de mais fácil aquisição, pois atualmente é fácil conseguir acumular conhecimentos corretos sobre aspectos diversos da sexualidade. Julgamos mais problemático é o aspecto de como utilizar e como vivenciar esses conhecimentos. Por isso mesmo não é obrigatório, como habitualmente se pensa, que o melhor professor para fazer educação sexual seja sempre o de biologia, que aliás está freqüentemente muito comprometido com os aspectos biológicos da sexualidade. É preferível, para exercer essa atividade, uma pessoa que tenha uma visão mais ampla do tema, porque se o sexo é biológico, a sexualidade é sobretudo cultural. E claro que existem professores de biologia que tem essa visão, sendo excelentes educadores sexuais, o que queremos dizer, no 
entanto, é que a educação sexual pode ser exercida por professores de qualquer formação. O que é importante é que essas pessoas, qualquer que seja sua área de atuação (matemática, línguas, educação física ou outra qualquer) recebam as informações adequadas para que bem possam exercer as atividades de educadores sexuais. 